\title{
Efficiency versus cost - A fundamental design conflict in energy science
}

\author{
C. Ohler \\ ABB Switzerland, Corporate Research - CH-5405 Baden-Dättwil, Switzerland
}

\begin{abstract}
Summary. - An essential design conflict in energy technology is the trade-off between efficiency and cost. The lecture introduces concepts that deal with this trade-off and discusses real world examples. Among the many definitions of efficiency, exergetic efficiency is the most rigorous and often the most adequate for analyzing the efficiency of a process. Exergy is the maximum work obtainable from a system as it comes into equilibrium with its environment. Exergetic efficiency is illustrated here with the heating of buildings. The right concept to analyze the trade-off between efficiency and the initial capital cost of equipment is the net present value analysis. We discuss two examples, overhead power lines and energy storage. Electrothermal energy storage is a new energy storage technology that builds on both concepts, optimization of exergetic efficiency and balancing of initial cost with that efficiency. Finally, non-technical barriers for energy efficiency are mentioned.
\end{abstract}

\section{1. - Introduction}

Most people, and even more so scientists and engineers, would readily agree that energy efficiency is a good thing. And yet there are many efficiency measures of households, commerce, and industry that are not implemented. The McKinsey greenhouse gas abatement cost curve [1] lists at least nine efficiency measures that would save carbon dioxide emissions of several gigatons per year and that are all either cost neutral or cash positive, that is they would even provide a net profit while reducing carbon dioxide emissions. 
Why are these measures not implemented? It is a purpose of this lecture to answer this question, to contribute to the efficiency discussion, to make it more complicated and more rational at the same time.

The lecture is structured into three sections. First, the concept of exergy is introduced. It is the base for the most useful of efficiency definitions, exergetic efficiency. Second, the main statement is discussed: efficiency is never the only aim of engineering work in energy science, efficiency has to be balanced with the initial capital cost. Finally, there is a short reminder that there are other non technical barriers for energy efficiency that are easily overlooked but important to consider in order to understand efficiency discussions.

\section{2. - Exergy and exergetic efficiency}

According to Wikipedia, "efficiency is ... the capability of a specific application of effort to produce a specific outcome ... with a minimum amount ... of waste, expense, or unnecessary effort" [2]. In the context of energy technology, we expect from a good efficiency definition a quantitative ranking of solutions (some metric that tells us which is the "best" one) and we also expect that $100 \%$ efficiency indicates an absolutely "perfect" solution that can not be improved upon at all.

The most common efficiency definition in energy technology is the definition of thermal efficiency, the ratio of the useful energy to the total input energy, $\eta=E_{\text {used }} / E_{\text {input }}$. This definition does not satisfy the two expectations in some of the relevant situations. Condensing boilers, for example, can have higher than $100 \%$ thermal efficiency, if the lower heating value of the fuel is chosen as the input energy. Also the ranking of various heating solutions (boilers, heat pumps, cogeneration of heat and power) is obscured by this efficiency definition. The issue is that energy appears in various forms very much unequal in character.

In what follows, we will introduce the concept of exergy, mainly following the lines of thought contained in [3] and [4]. Exergy is the energy that is available for use. It is the technically useful and economically valuable energy. The concept of exergy is usually part of the curriculum in thermodynamics as it is taught to mechanical engineering students [5], however, it is largely omitted from the thermodynamics courses that are taught to students in physics where the focus is more on the origin of classical thermodynamics in the microscopic statistical thermodynamics. Exergy is an essential analysis tool in energy science. The world has rather an exergy than an energy problem.

As a consequence of the second law of thermodynamics, energy conversions are subject to limitations, and energy can be thought of as being composed of two forms. On the one hand, exergy is that part of the energy that can in principle be completely converted into any other energy form. Examples for pure exergy are potential energy, kinetic energy, and electricity. Exergy is what we want and what we pay for. On the other hand, anergy is that part of the energy that is in equilibrium with the environment and that can not be converted into exergy. Actually it can not be converted into anything of use at all. An example for anergy is heat that is at ambient temperature, the temperature of the environment, such as the heat flux from the cooling tower of a thermal power plant. Even 


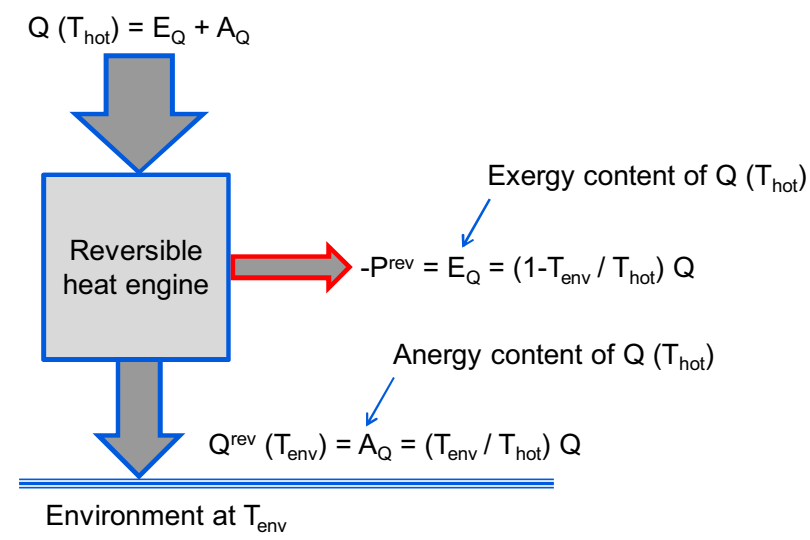

Fig. 1. - Exergy and anergy of heat are derived from the Carnot efficiency of a reversible heat engine.

though this is also a form of energy, it is rather a burden than a blessing, as it needs to be dispersed into the environment without doing harm. The distinction between exergy and anergy is at the origin of a rigorous definition of efficiency. Reversible processes conserve the amount of exergy, irreversible processes convert exergy into anergy.

The concept of exergy is most instructive in processes that involve heat (cf. fig. 1). The exergy and anergy of heat depend on the heat's temperature $T_{h o t}$ and the temperature of the environment $T_{\text {env }}$. With the Carnot efficiency in mind, that is the thermal efficiency of a reversible heat engine, it is easy to see that an amount of heat $Q$ at a temperature $T_{h o t}$ has an exergy content of $-P^{r e v}=E_{Q}=\left(1-T_{\text {env }} / T_{\text {hot }}\right) Q$ and an anergy content of $Q^{r e v}\left(T_{\text {env }}\right)=A_{Q}=\left(T_{\text {env }} / T_{\text {hot }}\right) Q$.

Any heat transfer accross a finite temperature difference creates entropy and thus destroys some exergy. This is illustrated in fig. 2 having in mind, e.g., a through-thewall heat exchanger between two fluids. In the absence of external heat losses all the heat is flowing from the hot side to the cold side, $Q_{\text {cold }}=Q_{\text {hot }}$. Because of the finite temperature difference, $T_{\text {cold }}$ is smaller than $T_{\text {hot }}$, and hence the entropy of the heat at the cold side $S_{\text {cold }}$ is larger than the entropy at the hot side $S_{\text {hot }}$. The irreversibility of the heat transfer creates additional entropy $S_{\text {irreversible. An equivalent description }}$ of this heat transfer process is given using exergy and anergy. The irreversibility of the heat transfer converts some of the exergy to anergy, so that the exergy $E_{\text {cold }}$ at the cold side is smaller than the exergy at the hot side $E_{h o t}$.

The heat exchanger is a first example for the usefulness of the exergetic efficiency definition. The ratio of cold and hot side exergies is a good metric to judge the quality of a heat exchanger. A better heat exchanger with a smaller temperature difference conserves more of the precious exergy.

We illustrate the concept of exergetic efficiency with the example of space heating. The exergy content of the heat flux $Q\left(T_{\text {room }}\right)$ used for space heating, $E_{Q}=$ $\left(1-T_{\text {env }} / T_{\text {room }}\right) Q$, is only $6.8 \%$ of the heat flux for a room temperature of $20^{\circ} \mathrm{C}$ and an 


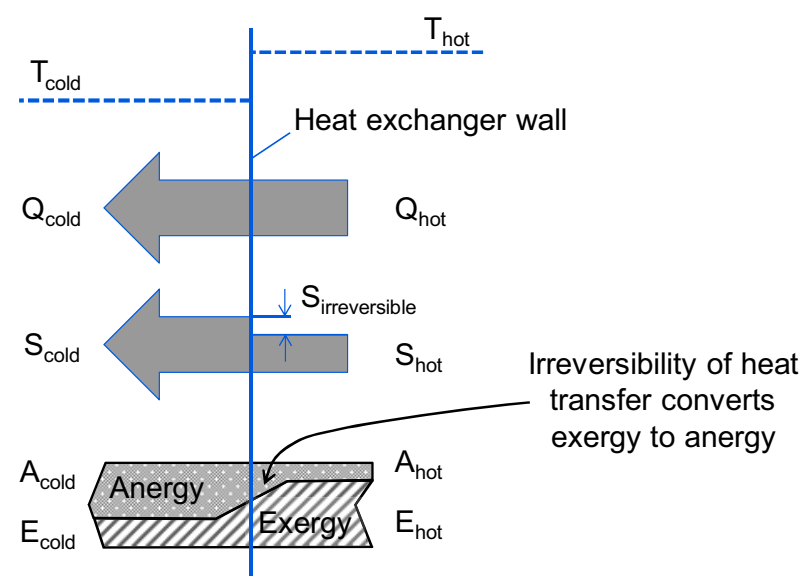

Fig. 2. - Heat transfer accross a finite temperature difference creates entropy and destroys some exergy.

environment temperature of $0^{\circ} \mathrm{C}$. The rest of the heat flux is anergy. In consequence, it has a low exergetic efficiency to do space heating with resistive heaters. The electricity supplying the heater is pure exergy, and only $6.8 \%$ of this exergy is eventually used in the space heating, the rest of the exergy is converted to anergy in the irreversible conversion of heat in the resistor.

Table I lists the calculated exergetic efficiencies (for a room temperature of $20^{\circ} \mathrm{C}$ and an environment temperature of $0^{\circ} \mathrm{C}$ ) for two cases. The left column contains the exergetic efficiency relative to the exergy of the incoming electricity. (This case would apply if the primary energy source for the electric power generation was hydropower or nuclear-power plants, where the conversion losses during the power generation are irrelevant.) The right column contains the exergetic efficiency relative to the chemical exergy of the coal for the case of a coal-powered electricity grid. We note that in the case of a coal power grid, the exergetic efficiency of resistive heating is depressed further to $2.4 \%$ of the initial

TABLE I. - Exergetic efficiencies of various methods of residential space heating for the simplified assumption of $20^{\circ} \mathrm{C}$ room temperature and $0^{\circ} \mathrm{C}$ outside temperature. For heat pump operation, a $60^{\circ} \mathrm{C}$ water cycle temperature and temperature differences of $10^{\circ} \mathrm{C}$ at both heat exchangers, the evaporator and the condensor of the cycle, was assumed.

\begin{tabular}{lcc}
\hline & $\begin{array}{c}\text { Hydropower } \\
\text { Nuclear power }\end{array}$ & $\begin{array}{c}\text { Coal-powered grid } \\
\text { (35\% thermal efficiency) }\end{array}$ \\
\hline Resistive & $6.8 \%$ & $2.4 \%$ \\
Combustion (no condensation) & $5.5 \%$ & $5.5 \%$ \\
Combustion with condensation & $6.1 \%$ & $6.1 \%$ \\
Heat pump & $17.6 \%$ & $6.1 \%$ \\
\hline
\end{tabular}


exergy! The exergetic efficiency of room heating by combustion of diesel fuel is of course independent of the primary supply of the power grid, however, it is also low at $5.5 \%$ and $6.1 \%$ without and with condensation of the water contained in the exhaust (the heat of condensation is used for preheating the air for combustion). The poor exergetic efficiencies are the combined effect of the irreversibilities of the combustion itself and of the degradation of the high-temperature heat from the high combustion temperature to the $20^{\circ} \mathrm{C}$ needed for the room heating. Note that the thermal efficiencies would be about $100 \%$ and give the misleading impression of being close to perfection.

Heating with heat pumps is fundamentally different. In that case, the huge amount of anergy is taken from the environment by "upgrading" the heat from the environment temperature to the room temperature - with the help of some exergy from the power grid that drives the compressor of the heat pump. The exergetic efficiency relative to the exergy of the incoming electricity (the case of hydropower or nuclear power) is much higher than combustion heating, even for the rather adverse boundary conditions assumed for the heat pump operation $\left(60^{\circ} \mathrm{C}\right.$ water cycle temperature and temperature differences of $10^{\circ} \mathrm{C}$ at both heat exchangers, the evaporator and the condensor of the cycle). It is interesting to note that the exergetic efficiency advantage disappears for the case of a coal powered electricity grid, where the improved efficiency of the heat pump is erased by the poor exergetic efficiency of the primary power generation.

We end the section by restating the main contributions to the efficiency discussion. Exergetic efficiency provides the most rigorous and often the only adequate efficiency definition. The choice of boundary conditions can influence an efficiency analysis, even if exergetic efficiencies are used. Heat pumps provide thermodynamically optimized space heating, in particular if temperature differences can be kept small (e.g. with a low temperature of the water cycle) and heat exchange surfaces large (e.g. using floor heating). Obviously, one should always examine first the possibility to reduce the required amount of space heating by improving the thermal insulation.

\section{3. - Not only efficiency, also cost}

Efficiency is never the only goal. Efficiency measures have the character of investments. Should one spend more money now in order to save money later? This is the question to be answered in many situations of energy science. In real industrial systems, the planners or designers optimize the trade-off between investment costs and efficiency. Fortunately, there is a straightforward entity, that needs to be optimized, the "net present value of cash flows" (NPV) [6].

The net present value of an investment is the sum of all discounted cash flows caused by the action of the investment

$$
\mathrm{NPV}=\sum_{t=0}^{T} C F_{t} /(1+r)^{t},
$$

where the sum extends over all years of the investment horizon from the moment of the 


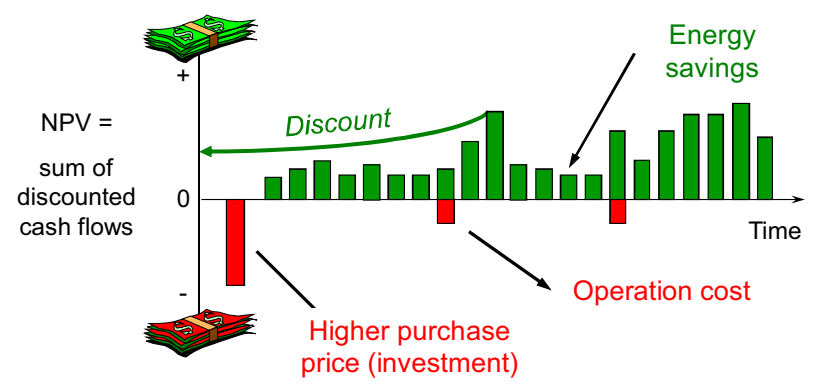

Fig. 3. - Illustration of the net present value of cash flows of an investment. Negative cash flows are the purchase price of the investment and the periodical operational costs. Positive cash flows are the energy savings (or any other kind of revenues).

investment $(t=0)$ until the end of life of the investment $(t=T)$. The summands are the cash flows $C F_{t}$ of each year $t$ discounted by the division through the discounting factor $(1+r)^{t} . r$ is the interest rate, and the discounting factor accounts for the time value of money, because one Euro in one year's time is worth $1 /(1+r)$ Euro today, as this amount would grow to become one Euro in a year's time if it was invested at an interest rate of $r$. The calculation of the NPV is illustrated in fig. 3 .

Figure 4 provides an example of the use of an NPV calculation to balance efficiency and investment cost. It shows the investment cost of a $380 \mathrm{kV}$ high voltage overhead line rated for $1700 \mathrm{MW}$ and the capitalized losses in Euro $/ \mathrm{km}$ as a function of the chosen line diameter in $\mathrm{mm}^{2}$. The capitalized losses of about 4000 Euro/kW are the result of an NPV calculation with eq. (1) with a time horizon of 30 years, an interest rate of $5 \%$,

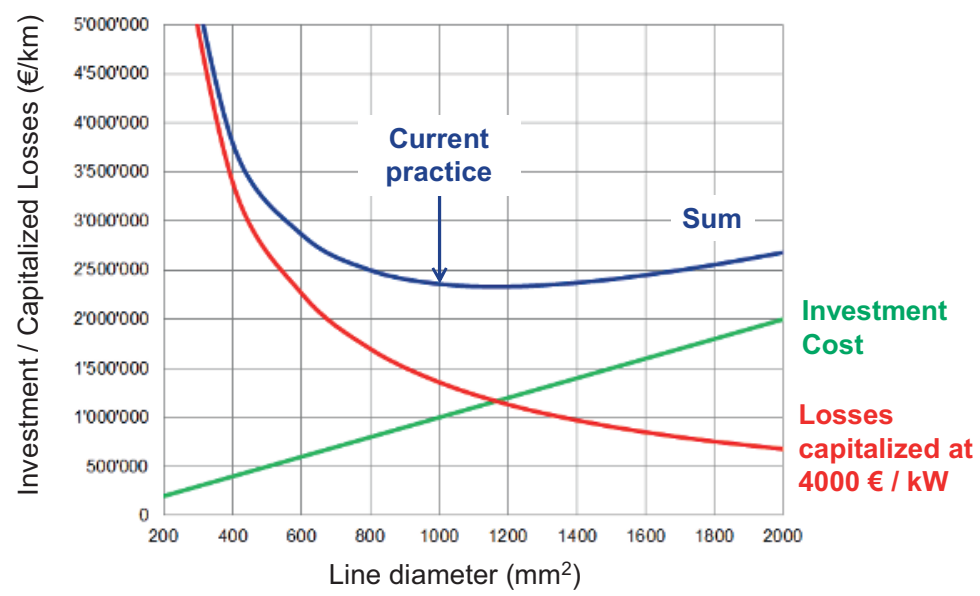

Fig. 4. - Investment cost and capitalized losses of a $1700 \mathrm{MW}, 380 \mathrm{kV}$ high voltage overhead line as a function of the overhead line diameter. 

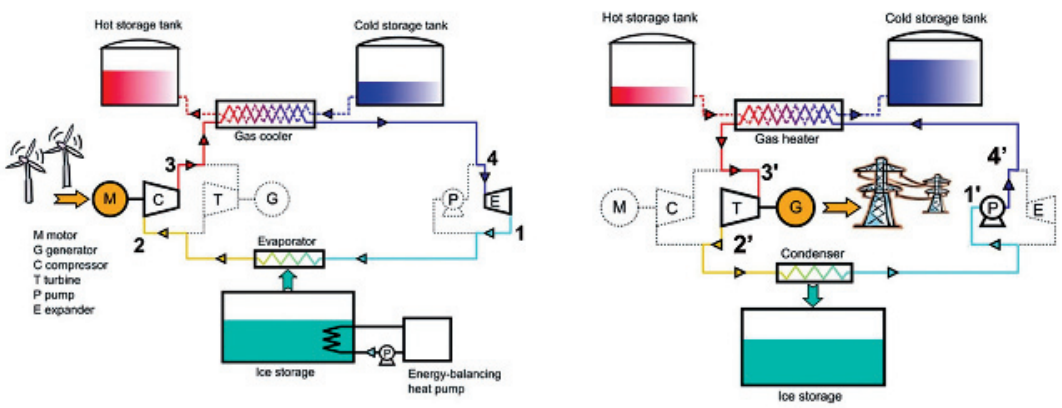

Fig. 5. - Schematic of an Electrothermal Energy Storage ("ETES") plant layout during charging (left) and discharging (right), numbers refer to a specific point along the cycle and the corresponding state of the carbon dioxide working fluid.

and a cost per $\mathrm{kWh}$ of 0.03 Euro (the losses in $\mathrm{kW}$ are assumed to be present during all 8760 hours of the year). The larger the line diameter, the lower the resistance of the line and the lower the losses, but the higher the investment cost due to the increased amount of aluminium and the increased amount of steel to support the heavier conductor. The minimum of the sum is close to the line diameter used in the current practice in power systems. This is the best compromise between efficiency and investment cost.

A further example illustrating both, the use of exergetic efficiency considerations and the trade-off between efficiency and cost, is Electrothermal Energy Storage ("ETES") [7]. It stores electricity in the form of heat in water and ice and using a reversible thermodynamic cycle based on transcritical carbon dioxide. Figure 5 shows a schematic of the plant layout during charging (left) and discharging (right), the numbers refer to a specific point along the cycle and the corresponding state of the carbon dioxide working fluid displayed in fig. 6 .

During times of excess electricity (charging) a carbon dioxide heat pump cycle is operated. The carbon dioxide working fluid evaporates in the evaporator taking away the latent heat of melting from cold liquid water that turns partially to solid ice (1-2). The gaseous carbon dioxide is then compressed into the supercritical region using the electric power that is to be stored (2-3). In the gas cooler, a counter flow heat exchanger, the carbon dioxide transfers the heat to water flowing from the fixed temperature cold water storage tank to the fixed temperature hot water storage tank (3-4). The expansion to the liquid state (4-1) closes the carbon dioxide cycle. Note that the transcritical heat pump cycle is an example for thermodynamically efficient heating.

During times of high demand for electricity, the cycle is reversed (right-hand side of fig. 5). It is now a power cycle, like the steam cycle of a coal power plant, but again with carbon dioxide as the working fluid. Liquid carbon dioxide is compressed with a pump $\left(1^{\prime}-4^{\prime}\right)$, it then receives the heat from the hot water in the counter flow heat exchanger now operated in the gas cooler mode $\left(4^{\prime}-3^{\prime}\right)$. It expands through a turbine $\left(3^{\prime}-2^{\prime}\right)$ converting the stored heat back to electricity. The condensation to a liquid that melts the ice produced during charging closes the carbon dioxide power cycle $\left(2^{\prime}-1^{\prime}\right)$. 


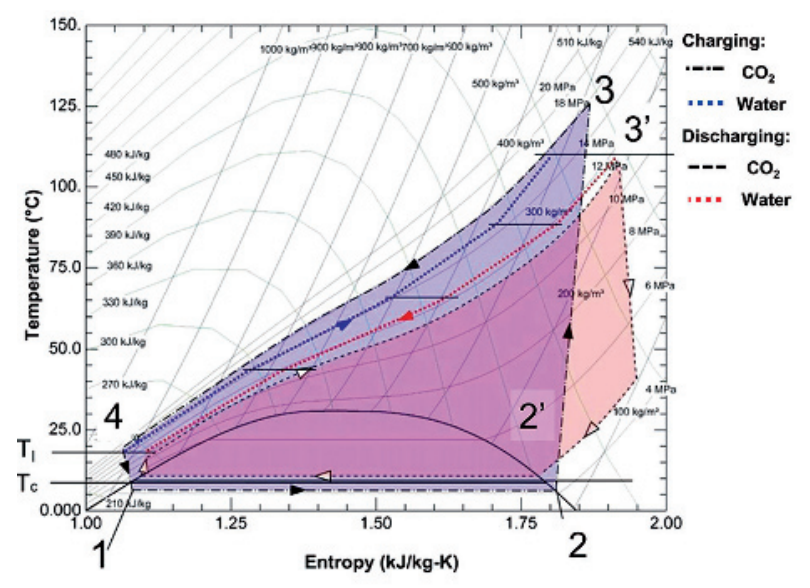

Fig. 6. $-T$ - $S$ diagrams of the transcritical carbon dioxide cycle, charging (counterclockwise) and discharging (clockwise), numbers refer to a specific point along the cycle and the corresponding state of the carbon dioxide working fluid.

The exergetic efficiency of the combined charging and discharging cycle can be estimated from fig. 6 that shows the $T$-S diagrams of the charging and discharging cycles. The key to the exergy efficient heat transfer between carbon dioxide and the liquid water at the hot side (3-4 and $\left.4^{\prime}-3^{\prime}\right)$ is the fact that the isobars of the supercritical carbon dioxide have a similar slope than the heat up and cool down curves of the water if the respective flows are adjusted accordingly. There is also a match of curves during the latent heat exchange from and to the ice in the evaporator/condensor. Recall from the previous section that a heat transfer accross a small temperature difference indicates a small amount of entropy generation and a high exergetic efficiency.

Electrothermal Energy Storage is also an example for the common trade-off between efficiency and cost. It is less efficient than lithium or sodium sulfur batteries, but much less expensive than these, as it is based on rotating turbomachines, that scale favourably to high power values.

\section{4. - Other barriers for energy efficiency}

We would like to add a paragraph about the non-technical obstacles that often prevent the introduction of energy efficiency measures. They come from the fact that decision makers not always maximize NPV. The economic and social reality is often more complex than that.

First, there is often a lack of awareness about the impact of investments on energy consumption. To analyze the impact of efficiency bears information costs. This is, for example, the reason why normal people, who are not technically educated, usually do not care about efficiency. Second, there are so called agency issues. The entity paying 
the bills for low efficiency is often distinct from the entity deciding about the initial investment. An example for this are the tenant and the homeowner. Third, it is an empirical fact that industrial companies and private consumers, as opposed to utilities, tend to require short payback times for their investments. Sometimes the payback time requirements can be shorter than what would seem to be rational from the point of view of economic self-interest. These non-technical obstacles should be kept in mind when analyzing efficiency questions.

\section{5. - Conclusion}

In this lecture, there are three main statements about the topic of efficiency in energy science. Exergy was introduced as a rigorous concept to analyze the efficiency of a process. The main point, however, is that one has always to balance the benefit from higher efficiency with the higher investment cost needed to achieve the benefits. This is usually done with a net present value analysis. Even in case of a positive net present value there might be other non-technical obstacles to introduce higher efficiency technologies, and this is why many efficiency measures of households, commerce, and industry are not being implemented.

$$
* * *
$$

I am grateful to Thomas Christen and Jaroslav Hemrle for teaching me thermodynamics for many years, and I would like to thank LiLiAn KAUFMANN for her forceful leadership of the Electrothermal Energy Storage project at ABB.

\section{REFERENCES}

[1] NAUClér T. and Enqvist P., Pathways to a low-carbon economy (McKinsey Global Institute) 2009.

[2] Efficiency, (wikipedia) retrieved on 23 October 2012, http://en.wikipedia.org/wiki/ Efficiency.

[3] Baehr H. D., Thermodynamik (Springer, Berlin) 1989.

[4] Bejan A., Advanced Engineering Thermodynamics (John Wiley \& Sons, New York) 1997.

[5] Moran M. J. and Shapiro H. N., Fundamentals of Engineering Thermodynamics (John Wiley \& Sons, Hoboken) 2008.

[6] Brealey R. A. and Myers S. C., Principles of corporate finance (McGraw-Hill, Boston) 2000.

[7] Mercangöz M., Hemrle J., Kaufmann L., Z'Graggen A. and Ohler C., Energy, 45 (2012) 407. 